\title{
Football Team Social Structure and Perceived Support for Reporting Concussion Symptoms: Insights from a Social Network Analysis
}

\author{
Heidi A. Wayment, PhD, Ann H. Huffman, PhD, Monica Lininger, PhD, LAT, ATC, and Patrick C. Doyle \\ Northern Arizona University
}

\begin{abstract}
Social network analysis (SNA) is a uniquely situated methodology to examine the social connections between players on a team, and how team structure may be related to self-reported team cohesion and perceived support for reporting concussion symptoms. Team belonging was positively associated with number of friendship ties (degree; $r=.23, p<.05$ ), intermediate ties between teammates (betweenness; $r=.21, p<.05)$, and support from both teammates $(r=.21, p<.05)$ and important others $(r=.21, p<.05)$ for reporting concussion symptoms. Additionally, an SNA-derived measure of social influence, eigenvector centrality, was associated with football identity $(r=.34, p<.01)$, and less support from important others $(r=-.24, p<.05)$ regarding symptom reporting. Discussion focuses on why consideration of social influence dynamics may help improve concussion-related education efforts.
\end{abstract}

Keywords: concussion education, social norms, social ties, team belonging, team structure

College football, a demanding high-contact sport, places players at risk for sport-related concussions (SRCs) and adverse future health consequences. ${ }^{1}$ Accordingly, it has been strongly argued that the goal of concussion education pro-

\section{Key Points}

This study used social network analysis (SNA) to examine relationships between social structure, identity perceptions, and concussion-reporting support in an NCAA Division I football team.

Team belonging was positively correlated with having more friends and being highly connected within the network.

Team belonging was positively correlated with perceived concussion-reporting support from teammates and important others.

The most socially influential members of the team reported

stronger football identity but lower concussion-reporting support from important others. grams should not only be to improve athletes' awareness of the signs of concussion and the risks of unreported injury $^{2}$ but also to change the social norms and make the reporting of SRC symptoms more acceptable and supported. ${ }^{3}$ Although SRC educational programs are required by all National Collegiate Athletic Association (NCAA) football programs, ${ }^{4}$ the evidence regarding their effectiveness for increasing concussion reporting is mixed. ${ }^{2,5-8}$ One problem may be how these educational efforts are typically delivered. Current mandated concussion education programs at the college level follow a familiar format: large groups of athletes seated in an auditorium listen to a lecture about concussion symptom recognition, the consequences of playing while concussed, and the importance of reporting symptoms. Sometimes, this information is combined with other health issues and health risks (e.g., alcohol and drug use, sexual health,

Wayment is with the Department of Psychological Sciences, Northern Arizona University, Flagstaff, AZ. Huffman, Lininger, and Doyle are with Northern Arizona University, Flagstaff, AZ. Wayment (Heidi.Wayment@nau.edu) is corresponding author. and sexual assault). This one-size-fits-all approach to concussion-related safety may not be sufficient. Relatedly, the recent Berlin consensus statement recommends that educational interventions be modified to take into account the needs, learning styles, and preferred learning strategies of target audiences. ${ }^{9}$ Another method to increase the effectiveness of health-related educational interventions is to consider group structure. In campaigns to reduce smoking and risky sexual behavior and increase healthy behaviors, such as vaccination, ${ }^{10-15}$ health messages are more effective if tailored to the social structure of the targeted group. ${ }^{14,15}$

The structure of well-defined groups, like football teams, can be analyzed. Social network analysis (SNA) is a well-known method that identifies the number and strength of social "ties" or connections among members of a group. ${ }^{16}$ Furthermore, this type of analysis not only creates a visual depiction of social connections among players on a team, but also allows for the calculation of centrality measures-indicators of social influence, connection, and popularity. ${ }^{16} \mathrm{~A}$ few studies have utilized SNA to examine how network dynamics influence athletic performance. ${ }^{17,18}$ In their informative article on the utility of SNA for researching issues related to athletic teams, Lusher and colleagues ${ }^{19}$ provide several examples of how SNA can help understand how influential members of a team drive social norms through their informal social influence within the team.

To date, no studies have utilized SNA in the context of concussion-symptom reporting attitudes. The goal of our study was to fill this gap by offering a preliminary examination of how SNA metrics of social influence may be related to one of the strongest predictors of concussion-symptom-reporting behavior-social norms, or athletes' perceptions of whether the important people in their lives support and encourage their reporting potential symptoms. Our study addresses three specific aims. Aim 1 was to describe the pattern of social ties in an NCAA Division I football team and examine if these 
patterns arise from similarities between players (homophily processes; e.g., players may select their friends on the team based on similar attributes). Thus, we examined if network ties were associated with player position group (i.e., offense or defense) or ethnicity. For Aim 2 we assessed whether basic SNA metrics associated with team structure were related to self-report measures of football identity, team cohesiveness, and team belonging. Our intention with this goal was to examine whether the SNA-derived metrics of structure and influence are related to players' perceptions of related constructs. The goal of Aim 3 was to investigate whether social norms supporting concussion-reporting behavior were shared by influential and noninfluential players alike. We examined the correlation between SNA metrics of centrality and perceived support for reporting concussion symptoms from one's teammates and important others.

\section{Methods}

\section{Participants}

All athletes on a Division I collegiate football team were invited to participate in our study. Ninety football athletes $(-70 \%$ of the eligible players listed on the official roster; $N=130$ ) completed the survey during the 2016 football season. In addition to questions about their current thoughts and feelings regarding concussionreporting behavior, some items also inquired about their past concussion-related experiences.

\section{Instrumentation}

Our survey contained items assessing concussion symptoms and reporting behaviors for the current season in which the data collection took place (2016) as well as the previous football season (2015). The survey also contained demographic questions (including year in school, player position group, current age, age when they began playing football), probes about players' perceptions of supportive social norms (from teammates, from "important others") regarding the reporting of concussion symptoms, and three team-related measures: football identity, team cohesiveness, and team belonging. Scale items, reference articles, ${ }^{20-25}$ Cronbach alpha values, and scale metrics are included in Table 1.

The social network was constructed by asking all members of the football team to nominate "up to 5 teammates" with whom they socialized, turned to for advice, and with whom they could talk

\section{Table 1 Scale Items and Sources}

\begin{tabular}{|c|c|c|c|}
\hline Construct & Items & $\begin{array}{l}\text { Cronbach } \\
\text { Alpha }\end{array}$ & $\begin{array}{l}\text { Analytic } \\
\text { Procedure }\end{array}$ \\
\hline \multirow{3}{*}{$\begin{array}{l}\text { Teammate } \\
\text { Social Norms }\end{array}$} & If I report what I suspect might be a concussion, my teammates will respect me. & \multirow[t]{3}{*}{.71} & \multirow[t]{3}{*}{ Mean of 3 items } \\
\hline & $\begin{array}{l}\text { If I report what I suspect might be a concussion, my teammates will think I } \\
\text { made the right decision. }\end{array}$ & & \\
\hline & $\begin{array}{l}\text { If I report what I suspect might be a concussion, my teammates will think more } \\
\text { of me. }\end{array}$ & & \\
\hline \multirow{4}{*}{$\begin{array}{l}\text { Social Support } \\
\text {-Others }\end{array}$} & People I know think I should report. & \multirow[t]{4}{*}{.89} & \multirow[t]{4}{*}{ Mean of 4 items } \\
\hline & People who are important to me think I should report. & & \\
\hline & It is expected of me to report. & & \\
\hline & People who are important would approve of my reporting. & & \\
\hline \multirow{12}{*}{$\begin{array}{l}\text { Football } \\
\text { Identity }^{c, d, e}\end{array}$} & My desire to continue my football career outweighs any of my academic goals. & \multirow[t]{12}{*}{.93} & \multirow[t]{12}{*}{ Mean of 12 items } \\
\hline & My desire to continue my football career outweighs any of my career goals. & & \\
\hline & My number one goal after I finish college football is to play professionally. & & \\
\hline & I have many goals related to football. & & \\
\hline & Most of my friends are athletes. & & \\
\hline & Football is the most important part of my life. & & \\
\hline & Being an athlete is an important part of who I am. & & \\
\hline & I spend more time thinking about football than anything else. & & \\
\hline & $\begin{array}{l}\text { I would be very depressed if I were injured and could not compete for my } \\
\text { school. }\end{array}$ & & \\
\hline & $\begin{array}{l}\text { My expectations after college include continuing to play football in a } \\
\text { professional league (NFL, overseas, etc.). }\end{array}$ & & \\
\hline & My involvement in football has influenced my day-to-day decision making. & & \\
\hline & I will likely play competitive football after my collegiate football career. & & \\
\hline \multirow[t]{3}{*}{ Cohesiveness ${ }^{\mathrm{f}}$} & The members of my team are cooperative with each other. & \multirow[t]{3}{*}{.92} & \multirow[t]{3}{*}{ Mean of 3 items } \\
\hline & The members of my team stand up for each other. & & \\
\hline & The members of my team know that they can depend on each other. & & \\
\hline \multirow[t]{3}{*}{ Belonging ${ }^{g}$} & I feel very connected with this team. & \multirow[t]{3}{*}{.84} & \multirow[t]{3}{*}{ Mean of 3 items } \\
\hline & Being a member of this team is very important to me. & & \\
\hline & I am very happy that I belong to this team. & & \\
\hline
\end{tabular}

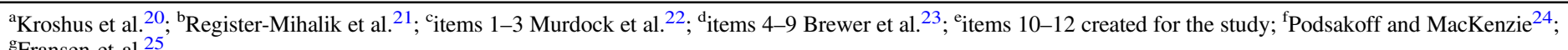
${ }^{\mathrm{g}}$ Fransen et al. ${ }^{25}$ 
about team-related issues. After creating the sociogram, we calculated four SNA-derived centrality measures. Eigenvector centrality assesses the extent that high-degree players are connected to other high-degree players and is measure of social influence. ${ }^{26}$ Degree, or the number of friendship ties per athlete, is an indicator of social support. ${ }^{16}$ An athlete high in betweenness centrality can be thought of as a "bridge" or "broker" that connects different parts of the team, a key conduit for the spread of new ideas or group norms. ${ }^{10,27}$ Closeness centrality refers to whether a player's location is more central or more peripheral in the network. Players with lower closeness centrality are most central to the network and most likely to be exposed to information. ${ }^{16,24}$ These metrics were significantly correlated in the expected directions ( $r$ s ranged from .19-.70, $p s<.05$ or lower).

\section{Procedures}

During the 2016 season we collected data from members of one NCAA Division I football team as part of a larger ongoing study about concussion-reporting behavior. ${ }^{28}$ Prior to data collection, a research team member explained the purpose of the study, answered any questions, and then obtained informed consent from each participant as approved by the university's institutional review board. Athletes completed the paper-pencil survey in a large lecture hall, which took approximately 25 to $30 \mathrm{~min}$ to complete. Once participants had completed the questionnaire they received a $\$ 10$ gift card.

\section{Statistical Analysis}

SNA was completed using UCINET $6^{26}$ software package and network drawings were made with NetDraw. ${ }^{27}$ Pearson correlations were conducted with SPSS (version 24.0; IBM Corp, Armonk, NY). To describe the pattern of social ties in an NCAA Division I football team (Aim 1), players' nominations of friends were transformed into a $90 \times 90$ adjacency matrix with a "1" entered when there was a "tie" between two players and used to draw a sociogram to visually inspect the social network structure. Quadratic assignment procedure (QAP) correlations were used to examine if network ties were associated with race and position group. ${ }^{22}$ QAP correlations are permutation procedures comparing 50,000 randomly-generated identity matrices representing shared position group (" 1 " if two players shared a position group and " 0 " if not) and shared racial identity ("1" if two players shared ethnicity and "0" if not). ${ }^{26} P$ values generated from QAP correlations represent how often randomly-generated correlations, as large as those obtained in the data, occur by chance. Accordingly, we also report the range of correlations that are generated by this procedure.

To examine whether basic team structure SNA-metrics were related to self-report measures (Aim 2) we first used UCINET ${ }^{29}$ to compute four measures of centrality: degree, eigenvector, betweenness, and closeness. Then, we computed correlations between these four metrics with three self-report measures (team cohesion, football identity, team belonging) and SNA-derived centrality metrics (degree, eigenvector, betweenness, and closeness). To examine whether social norms supporting concussion-reporting behavior were shared by influential and noninfluential players alike (Aim 3), we correlated SNA-derived metrics with two measures of social support for concussion-reporting behavior: from teammates and from important others.

\section{Results}

\section{Descriptive Information}

All participants were male (age: $19.50 \pm 1.30$ years), primarily freshmen $(\mathrm{n}=55)$ and sophomores $(\mathrm{n}=21)$. Participants averaged $10.57 \pm 2.74$ years of playing football, and, on average, began playing football at the age of $9 \pm 3$ years old. Just over half of our sample $(53 \%)$ indicated that they, sometime during their football career, had a concussion that was undiagnosed. Players provided information about concussion-related experiences from the previous season (2015). Nearly one-quarter (23\%) of the sample said they had reported their symptoms to a coach or athletic trainer. Eighteen percent of the players reported being diagnosed with a concussion in the current season (2016), a number that matched exactly with the records kept by the athletic trainers during the 2016 season. ${ }^{30}$ Table 2 provides means and standard deviations of self-report measures (team cohesion, football identity, team belonging, and social norms) and SNA-derived centrality metrics (degree, eigenvector, betweenness, and closeness). Team cohesion and team importance were rated well above the scale midpoint (5-point scale), followed by social norms from important others and football importance, also above the scale midpoint. Social norm support from teammates was below the scale midpoint.

Table 2 Descriptive Statistics and Correlations Among All Study Variables

\begin{tabular}{|c|c|c|c|c|c|c|c|c|c|c|}
\hline Variable & Mean & SD & 2 & 3 & 4 & 5 & 6 & 7 & 8 & 9 \\
\hline 1. Degree & 4.73 & 1.71 & $.55 * *$ & $.70 * *$ & $-.64 * *$ & -.06 & -.05 & $.27 * *$ & $.23 *$ & $.23 *$ \\
\hline 2. Eigenvector & 0.07 & 0.08 & - & $.19+$ & $-.33 * *$ & -.06 & $-.24 *$ & $.34 * *$ & $.20+$ & .11 \\
\hline 3. Betweenness & 147.62 & 141.60 & & - & $-.54 * *$ & -.02 & -.02 & .15 & $.21 *$ & .13 \\
\hline 4. Closeness & 383.38 & 72.62 & & & - & .04 & .01 & -.14 & -.13 & -.07 \\
\hline 5. Social norms: teammates & 2.11 & 0.62 & & & & - & .11 & .09 & $.21 *$ & .04 \\
\hline 6. Social norms: important others & 3.84 & 0.72 & & & & & - & .09 & $.27 * *$ & .15 \\
\hline 7. Football identity & 3.40 & 0.67 & & & & & & - & $.57 * *$ & $.36 * *$ \\
\hline 8. Team belonging & 4.11 & 0.75 & & & & & & & - & $.44 * *$ \\
\hline 9. Team cohesion & 4.21 & 0.70 & & & & & & & & - \\
\hline
\end{tabular}

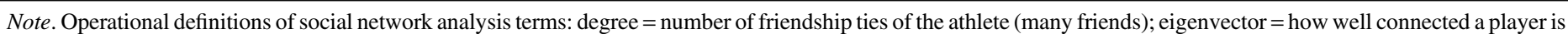

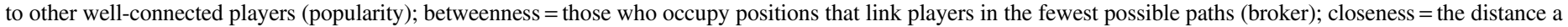
player on the team is linked to everyone else (peripheral).

$+p<.07$. * $p<.05$. ** $p<.01$. 


\section{Patterns of Social Ties}

For Aim 1 we examined if network ties were associated with player position group (i.e., offense or defense) or ethnicity. The football team friendship network consisted of 250 ties, with an average of 2.78 ties per player. The network's overall connectedness coefficient was .647 , indicating that about $65 \%$ of player dyads were connected to each other ( $35 \%$ of the pairs were not connected). Players on the team averaged 2.78 ties to other players. Consistent with a homophily hypothesis, ${ }^{26}$ players from the same general football position group (e.g., offense or defense) were more likely to be friends (QAP correlation $=.06, p<.0001$, minimum observed $=-.065$, maximum observed $=.082$ ). That is, the percentage of time a correlation of .06 was observed was less than 1 out of a thousand iterations (out of the 50,000 matrix correlations computed). There was also evidence of ethnic homophily (QAP correlation $=.06, p<.0002$, minimum observed $=-.061$, maximum observed $=.067)$. Figure 1 depicts the football team friendship network with node shapes denoting general offensive and defensive players. The nodes are sized by eigenvector centrality. As depicted in Figure 1, a clearly identifiable subgroup of influential players consists of about eight defensive players and four offensive players.

\section{SNA Metrics and Identity, Belonging, and Cohesion}

To examine whether basic SNA metrics associated with team structure were related to self-report measures (Aim 2), we computed Pearson correlations between four measures of network centrality (degree, eigenvector, betweenness, and closeness) and three self-report measures (football identity, team cohesiveness, and team belonging). Correlations (zero-order correlations presented in Table 2) revealed that players with more friends (degree) reported higher scores on football identity $\left(R^{2}=.07\right)$, team belonging $\left(R^{2}=.05\right)$, and team cohesion $\left(R^{2}=.05\right)$. Influential players (eigenvector centrality) reported stronger football identity $\left(R^{2}=.12\right)$. Players situated between two or more players, who are described as "brokers" of information (betweenness) reported higher scores on team belonging $\left(R^{2}=.04\right)$.

Player influence and perceived support. In order to examine whether influential and noninfluential players felt the same level of support for reporting concussion symptoms, we correlated SNAderived centrality metrics (degree, eigenvector, betweenness, and closeness) with two measures of support for reporting (from teammates and important others) (Aim 3). Eigenvector centrality, the most robust SNA measure of social influence in a group, was related to lower perceived social norms from important others

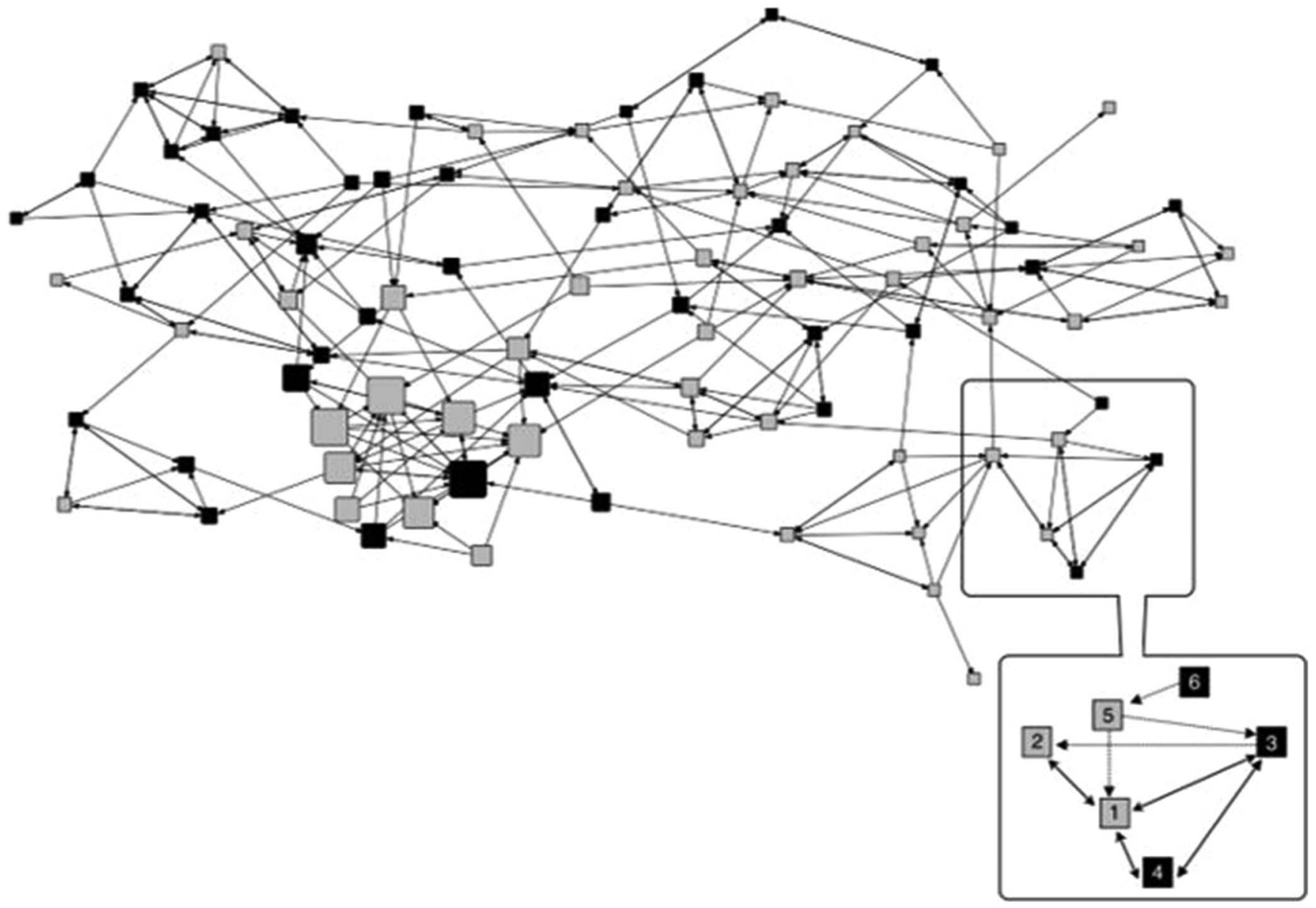

Figure 1 - Sociogram of National Collegiate Athletic Association (NCAA) football team friendships. This figure depicts directed friendship ties between players. Offensive players are depicted as black squares; defensive players are depicted as grey squares. Node size is based on eigenvector centrality (larger squares $=$ more influential players). The close-up illustration (bottom right) shows several examples of network patterns. For example, there are three triads (1-3-4, 1-5-3, and 1-2-3), with triad 1-3-4 as a "fully closed" triad; players 1 and 5 serve as "brokers" between nonconnected players; player 1 has four incoming ties and three outgoing ties. 
$\left(R^{2}=.06\right)$. None of the other centrality metrics were correlated with teammate social norms, indicating that all members of the team reported the same level of support from teammates, which was, on average, relatively low (2.11 on a 5-point scale).

\section{Discussion}

Nearly 15 years ago, McCrea and colleagues, ${ }^{2}$ offered compelling evidence and effectively argued for the importance of education to improve athletes' awareness of the signs of concussion and the risks of unreported injury. Important athletic-program stakeholders and athletic trainers have helped ensure that these goals have largely been met-athletes are regularly educated about the signs of concussion and risks of unreported injury. ${ }^{4}$ On the basis of our investigation, we suggest that understanding the social structure of a football team may aid in the design of educational efforts to support concussion-symptom reporting behavior in collegiate football athletes.

Our first aim was to describe the pattern of social ties in an NCAA Division I football team and examine whether players are more likely to have friends that are similar on the basis of position group or ethnicity (i.e., homophily). We created a sociogram of the football team, sized the nodes (each player) by position group (offense or defense) and sized the nodes by the SNA-created metric of social influence (larger node $=$ greater social influence). As seen in Figure 1, the sociogram also shows the most popular players (those with the most "ties") and those that serve as social "brokers" (those connecting two other players). The structural information depicted in a sociogram can be helpful for stakeholders understanding the flow of information in a team. Our homophily analyses found that "friendship ties" between players were more likely between players who shared a position group or ethnicity. This finding is supported by many other studies showing the power of similarity and propinquity in the selection of friendships.

One of the documented advantages of using social network analysis is that it allows the simultaneous examination of team social structure and team members' self-report measures. ${ }^{31}$ Our second aim capitalized on this dimension of SNA analysis and examined whether SNA-derived metrics were related to players' self-reported levels of football identity, team cohesiveness, and team belonging. Our exploratory analyses found that SNA measures of popularity (eigenvector centrality), connectedness (degree), and brokering (betweenness) were differentially associated with self-reported measures of belonging, cohesion, and football identity. Further, we found that these SNA-derived measures were associated in expected ways with self-reported ratings of closeness to the team, team cohesion, and football identity, as shown in Table 2. Specifically, degree was positively associated with closeness, cohesion, and identity; eigenvector centrality was associated with identity and belonging; and betweenness was associate with belonging. These findings support earlier longitudinal research showing an association between the number of ties (degree) and perceived group cohesion. ${ }^{31}$ Although the shared variance between our SNA-derived metrics and self-report measures was modest (ranged from .04 to .12), the empirical overlap between the SNA-derived metrics and self-report measures provides some evidence that the SNA metrics are detecting important structural features of a team's social network. ${ }^{19}$

Our third aim concerned whether players reported similar levels of support for the reporting of concussion symptoms, or whether their perception of support differed by their social position on the team. Educational interventions typically target all players at once, but do all players perceive the support for reporting symptoms similarly? Similar to previous research findings, we found that support for symptom reporting among members of a collegiate football team to be relatively low., 2,5 Players that rated the highest level of support for reporting symptoms, both from teammates and important others, were those who reported stronger "team belonging." The most concerning finding was that those players who were identified as most influential (i.e., those who have more ties to other popular players) were not only those who reported the highest levels of football identity, but also were those who perceived the least support from important others to report symptoms. The proportion of variance in our measure of perceived support from important others accounted for by the SNA-derived measure of social influence (eigenvector centrality) was $6 \%$.

\section{Limitations}

Our results are limited in that we analyzed members from just one type of sport, football, and from one NCAA Division I football team. Furthermore, our sample consisted primarily of freshmen and sophomores $(83 \%)$. Thus, our results are not representative of the older members of the team we investigated, other NCAA Division I football teams, or participants in other sports. Another limitation is that our study provided only a single snapshot of athletes' perceptions of concussion reporting social norms at the end of their season.

\section{Clinical Implications}

The implications of our findings relate directly to how athletic trainers may consider how to improve educational interventions to increase concussion-symptom reporting in athletes. In other work, ${ }^{32}$ we conducted in-depth interviews with collegiate football program athletic trainers and found that their close working relationships with athletes provided them with insight concerning which members of the team were influential, well-connected, and popular. In cases where this information is not known, brief surveys, which are easier to administer and tabulate (than SNA analyses) could be utilized to have a better understanding of athletes' sense of belonging ${ }^{25}$ and team cohesion. ${ }^{24}$ Although these two measures were moderately correlated in our sample, there are nuanced differences. For example, cohesiveness is the perception about how team members stand up for one another whereas team belonging is more of an appraisal of a player's satisfaction of being a member of the team and feeling connected to other members of the team. The take-away message for athletic trainers is that they can use information regarding team social structure, whether collected using SNA methodology, self-report surveys, or their own observations, to work with coaches, team captains, and other key stakeholders to take important social dynamics into account when administering concussion education protocols.

Our findings may provide some specific ways to target athletes for intervention efforts. In their review of how SNA can be used to improve health behavior interventions, Latkin and Knowlton ${ }^{33}$ effectively argue for the strategy of identifying influential members of the group (also called "opinion leaders" or "change agents") and providing specialized training and education to these individuals. Ideally, influential players will also model the desired behaviorconcussion-symptom-reporting behavior and support for others to report symptoms - in ways that are consistent, accepted by fellow football players, and are publicly rewarded by the coaches and athletic trainers. Such modeling by influential members of the team 
could increase team members' self-efficacy and strengthen team social norms regarding that behavior.

Other recommendations include (a) working collaboratively with specific players and small groups of athletes to find innovative messages about the importance of reporting that tie directly to their values and (b) considering interventions or activities that strengthen a sense of team cohesion and team belonging. Recall our results indicated that members of the team that reported greater team belonging also reported greater levels of support for reporting symptoms. This idea is qualified by our finding that the most influential members of the team may not share the perception of being supported by important others for reporting symptoms. Educational messages aimed at the most influential members of the team may benefit from messages that tap into the importance of their strong identification as football players. Athletic trainers could not only develop tailored interventions that help convince influential players about the importance of symptom reporting and help them become "role models" for other players, but also monitor the success of these efforts. ${ }^{10,31,33}$

\section{Future Research}

Our initial exploration of the utility of SNA in the context of teamrelated concussion-reporting attitudes holds promise for researchers interested in understanding how to change the "culture of concussion-reporting behavior." In many areas of health behavior research, it is common to examine how, over time, social ties influence the adoption of health-related attitudes (so-called "influence" effects) and how attitudes affect social ties (so-called "selection" effects). ${ }^{33}$ As has been researched in the area of young adults' sexual health decision making, ${ }^{34}$ future research could examine whether team friendships influence players' concussion-related attitudes or whether concussion-related attitudes influence team friendships. Understanding such social dynamics within a football team may aid our understanding of social influence processes related to the formation of concussion-related attitudes and behavior. The finding that adolescent school friendships cluster according to sexual experience, knowledge, and attitudes strengthens the evidence base for health interventions using social diffusion approaches. For example, assessment of athletes' participation in educational efforts and athletes' ratings of the intervention content could be mapped onto the network structures to examine where there might be clusters of supportive and unsupportive views about the intervention content. A practical implication of longitudinal SNA research is the ability to examine what types of messages or information are most effective for which players on a team, and how to tailor educational messaging to maximize attitude change on an athletic team.

\section{Conclusion}

Our research seeks to inform the next generation of educational interventions to consider important social influence dynamics for not only the creation of educational materials, but also ensure that they are accepted and transmitted through the team social network. It likely comes as no surprise to athletic trainers, who have developed close working relationships with coaches and athletes alike, that identifying potential "opinion leaders" 33 could be a fruitful next step in the development of educational intervention materials. Studies and programs that ignore these relations miss out on the opportunity to advance the science of human behavior and, for interventions, potentially fall short of their true capacity to improve outcomes. Social network theory specifies the conditions under which people are likely to be connected and how these individuals influence one another.

\section{References}

1. Kerr ZY, Thomas LC, Simon JE, McCrea M, Guskiewicz KM. Association between history of multiple concussions and health outcomes among former college football players: 15-year follow-up from the ncaa concussion study (1999-2001). Am J Sports Med. 2018;46(7): 1733-1741. PubMed ID: 29620911 doi:10.1177/0363546518765121

2. McCrea M, Hammeke T, Olsen G, Leo P, Guskiewicz K. Unreported concussion in high school football players: implications for prevention. Clin J Sport Med Off J Can Acad Sport Med. 2004;14(1):13-17. doi:10.1097/00042752-200401000-00003.

3. Kroshus E, Garnett BR, Baugh CM, Calzo JP. Social norms theory and concussion education. Health Educ Res. 2015;30(6):1004-1013. PubMed ID: 26471918 doi:10.1093/her/cyv047

4. NCAA Academic and Membership Affairs Staff. 2016-2017 NCAA Division I Manual. Indianapolis, IN: NCAA; 2016.

5. Meehan WP, Mannix RC, O'Brien MJ, Collins MW. The prevalence of undiagnosed concussions in athletes. Clin J Sport Med. 2013;23(5):339-342. PubMed ID: 23727697 doi:10.1097/JSM. 0b013e318291d3b3

6. Asken BM, McCrea MA, Clugston JR, Snyder AR, Houck ZM, Bauer RM. "Playing through it": Delayed reporting and removal from athletic activity after concussion predicts prolonged recovery. $J$ Athl Train. 2016;51(4):329-335. PubMed ID: 27111584 doi:10.4085/ 1062-6050-51.5.02

7. Baugh CM, Kroshus E, Kiernan PT, Mendel D, Meehan WP III. Football players' perceptions of future risk of concussion and concussion-related health outcomes. J Neurotrauma. 2017;34(4): 790-797. PubMed ID: 27526721 doi:10.1089/neu.2016.4585

8. LaRoche AA, Nelson LD, Connelly PK, Walter KD, McCrea MA. Sport-related concussion reporting and state legislative effects. Clin J Sport Med. 2016;26(1):33-39. PubMed ID: 25894530 doi:10.1097/ JSM.0000000000000192.

9. McCrory P, Meeuwisse W, Dvořák J, et al. Consensus statement on concussion in sport-the 5th International Conference on Concussion in sport held in Berlin, October 2016. Br J Sports Med. 2017;51(11): 838-847. doi:10.1136/bjsports-2017-097699

10. Wasserman S, Faust K. Social Network Analysis: Methods and Applications. New York, NY: Cambridge University Press; 1994.

11. Maya-Jariego I, Holgado D. Network analysis for social and community interventions. Psychosoc Interv. 2015;24(3):121-124. doi:10. 1016/j.psi.2015.10.001

12. Valente TW, Palinkas LA, Czaja S, Chu KH, Brown CH. Social network analysis for program implementation. PLOS ONE. 2015; 10(6):e0131712. PubMed ID: 26110842 doi:10.1371/journal.pone. 0131712

13. Valente T. Social Networks and Health: Models, Methods, and Applications. Oxford, UK: Oxford University Press; 2010.

14. Valente TW. Network interventions. Science. 2012;337(6090): 49-53. PubMed ID: 22767921 doi:10.1126/science.1217330

15. Rogers E. Diffusion of Innovations. New York, NY: Free Press; 2003.

16. Borgatti S, Everett M, Johnson J. Analyzing Social Networks. Los Angeles, CA: Sage; 2013.

17. Salim M, Brandao W, Camp O, Filipe J, eds. ICEIS 2018: Proceedings of the 20th International Conference on Enterprise Information Systems: Funchal, Madeira, Portugal, March 21-24, 2018. Vol. 1. Setúbal, Portugal: SCITEPRESS - Science and Technology Publications, Lda; 2018. 
18. Mclean S, Salmon PM, Gorman AD, Dodd K, Solomon C. Integrating communication and passing networks in football using social network analysis. Sci Med Footb. 2019;3(1):29-35. doi:10.1080/24733938. 2018.1478122

19. Lusher D, Robins G, Kremer P. The application of social network analysis to team sports. Meas Phys Educ Exerc Sci. 2010;14(4):211224. doi:10.1080/1091367X.2010.495559

20. Kroshus E, Baugh CM, Daneshvar DH, Viswanath K. Understanding concussion reporting using a model based on the theory of planned behavior. J Adolesc Health. 2014;54(3):269-274.e2. doi:10.1016/j. jadohealth.2013.11.011

21. Register-Mihalik JK, Guskiewicz KM, McLeod TC, Linnan LA, Mueller FO, Marshall SW. Knowledge, attitude, and concussionreporting behaviors among high school athletes: A preliminary study. J Athl Train. 2013;48(5):645-653.

22. Murdock JL, Strear MM, Jenkins-Guarnieri MA, Henderson AC. Collegiate athletes and career identity. Sport Educ Soc. 2016;21(3): 396-410. doi:10.1080/13573322.2014.924920.

23. Brewer BW, Van Raalte JL, Linder DE. Athletic identity: Hercules' muscles or Achilles heel? Int J Sport Psychol. 1993;24(2):237-254. doi:10.1177/104973239800800506

24. Podsakoff P, MacKenzie S. Organizational citizenship behaviors and sales unit effectiveness. J Mark Res. 1994;31(3):351-363. doi:10. 1177/002224379403100303.

25. Fransen K, Vanbeselaere N, De Cuyper B, Coffee P, Slater MJ, Boen F. The impact of athlete leaders on team members' team outcome confidence: a test of mediation by team identification and collective efficacy. Sport Psychol. 2014;28(4):347-360. doi:10.1123/tsp.20130141

26. Borgatti S, Everett M, Freeman L. Ucinet for Windows: Software for Social Network Analysis. Harvard, MA: Analytic Technologies; 2002.
27. Borgatti S. Netdraw Network Visualization. Harvard, MA: Analytic Technologies; 2002.

28. Craig DI, Lininger MR, Wayment HA, Huffman AH. Investigation of strategies to improve concussion reporting in American football. Res Sports Med. 2019:1-13. Ahead of Print. doi:10.1080/15438627. 2019.1586706

29. Borgatti, S.P., Everett, M.G., \& Freeman, L.C. (2017). UCINET. In R. Alhajj \& J. Rokne (Eds.), Encyclopedia of Social Network Analysis and Mining (pp. 237-259). New York, NY: Springer.

30. Wayment H, Craig D, Huffman A, Lininger M. A simple field-based tool to assess concussion reporting behavior: Implications for clinical practice and research. Am J Prev Med. 2019;56(2):323-330. PubMed ID: 30554973 doi:10.1016/j.amepre.2018.10.007.

31. Gesell SB, Barkin SL, Sommer EC, Thompson JR, Valente TW. Increases in network ties are associated with increased cohesion among intervention participants. Health Educ Behav. 2016;43(2):208-216. PubMed ID: 26286298 doi:10.1177/1090198115599397

32. Lininger MR, Wayment HA, Craig DI, Huffman AH, Lane TS. Improving concussion-reporting behavior in National Collegiate Athletic Association Division I football players: Evidence for the applicability of the socioecological model for athletic trainers. $J$ Athl Train. 2019;54(1):21-29. PubMed ID: 30721092 doi:10.4085/10626050-47-18

33. Latkin CA, Knowlton AR. Social network assessments and interventions for health behavior change: A critical review. Behav Med. 2015;41(3):90-97. PubMed ID: 26332926 doi:10.1080/08964289. 2015.1034645

34. McCann M, Broccatelli C, Moore L, Mitchell K. Distribution of sexual health knowledge and attitudes in adolescent social networks: social network analysis of data from the STIs and Sexual Health feasibility study. The Lancet. 2018;392:S60. doi:10.1016/S01406736(18)32047-6 